Mini-Review

\title{
Insights into the structure of the subtelomeric chromosome segments*
}

\author{
Máximo E. Drets \\ Department of Human Cytogenetics and Quantitative Microscopy, Instituto de Investigaciones Biológicas Clemente Estable, \\ Avda. Italia 3318, Montevideo,Uruguay.Fax:+598-2-487-5548.E-mail: drets@chasque.apc.org
}

\begin{abstract}
*Presented at the International Graduate School Course and Workshop on "New Approaches in the Study of Radiation-Induced and Cancer-Associated Chromosomal Aberrations"
\end{abstract}

\section{INTRODUCTION}

The study of telomeric/subtelomeric areas is becoming of increasing cytological importance since this multifunctional chromosome segment intervenes not only in keeping constant the number and structure of the chromosomes of each species but also is involved in cancer development and cell senescence (Zakian, 1989; Blackburn and Greider, 1995; Greider, 1998).

In the present contribution, we briefly review the major aspects of the molecular composition of the telomere segment. Besides, we discuss its possible relationship to some unusual observations that we made on the subtelomeric areas of Chinese hamster ovary $(\mathrm{CHO})$ and human chromosomes and the models we used to substantiate the reality of the subtelomeric structures found by us. Finally, we examine some problems not yet well clarified on this critical chromosome segment.

\section{THE TELOMERIC/SUBTELOMERIC PICTURE: (I)}

\section{DNA repetitive arrays. A simplified view of the telomere?}

Considerable advances have occurred in molecular research of telomeres and subtelomeric regions. Blackburn and Gall (1978) demonstrated first that Tetrahymena telomeres contain DNA tandem repeats. This finding was confirmed in other organisms from single-celled eukaryotes to mammals and higher plants (Blackburn and Szostak, 1984; Zakian, 1989). In human chromosomes, a telomeric repeated sequence (TTAGGG) $)_{\mathrm{n}}$ has been found by fluorescent hybridization (Moyzis et al., 1988) which was subsequently detected in the pericentric heterochromatic region and in non-telomeric sites in chromosomes of other mammals (Meyne et al., 1990a). Middle repetitive elements or telomere-associated sequences have also been found in subtelomeric regions. Telomere-associated long tandem arrays of repeated units were found in Chironomus (Saiga and Edstrom, 1985) and in Secale, appearing as large blocks of C-banded heterochromatin containing a simple tandem array (Bedbrook et al., 1980). Digital fluorescence microscopy has been used for telomere repeat sequences detection and telomere length measuring (Poon et al., 1999). A fragment of Drosophila melanogaster DNA contains sequences homologous to DNA found at the ends of the polytene chromosomes and to the pericentric sequences present in the beta heterochromatin (Young et al., 1983). Arrays of repetitive nucleotide sequences, believed to be sites for protein and ribonucleoprotein binding, are present not only at the ends of human chromosomes but also at numerous interstitial sites and at the paracentric areas (Wells et al., 1990). Telomeric sequences are also found in non-telomeric sites in other vertebrate chromosomes (Meyne et al., 1990b). Using a biotinylated plant telomeric probe, Schubert (1992) observed fluorescent signals at terminal and interstitial positions and polymorphism in the centromeric area of Vicia faba chromosomes.

Middle repetitive sequences are also found in subtelomeric segments and in the pericentric heterochromatic region of many chromosomes (Blackburn and Szostak, 1984; Meyne et al., 1990b). Telomere DNA has been divided into structural and functional domains. Immediately adjacent to the telomere repeats are telomere sequences constituting a third structural domain formed by very dynamic and numerous telomere-associated sequences which are mainly located in the sub-telomeric region (Henderson, 1995).

Research on the distribution of telomeric and internal (TTAGGG) $\mathrm{n}$ repeats was carried out by Steinmüller $e t$ al. (1993) using biotinylated repetitive whole chromosome paint and telomere DNA probes at the electron microscope level. They detected terminal, subterminal and internal repeats in human chromosomes. The subtelomeric repeats were observed close to the terminal ones in sister-chromatids embedded in the chromatin of the chromosome terminus.

Balajee et al. (1994) analyzed the intra-chromosomal 
telomeric sequences in restriction enzyme-treated $\mathrm{CHO}$ and Chinese hamster embryonic (CHE) cells, describing that in $\mathrm{CHO}$ cells (TTAGGG) $)_{\mathrm{n}}$ repeats are mainly localized near the centromeric regions of many of the chromosomes while in $\mathrm{CHE}$ chromosomes the telomeric repeat sequences are found at both the terminal and centromeric regions.

\section{THE TELOMERIC/SUBTELOMERIC PICTURE: (II)}

Telomeric proteins: Completing the view?

Telomeres are specialized DNA/protein complexes that comprise the ends of eukaryotic chromosomes with proteins that bind sequence specifically to telomeric DNA, capping the chromosome ends, thus preventing nucleolytic degradation and end-to-end ligation.

The ribonucleoprotein telomerase is responsible for telomeric maintenance and partly compensates the progressive shortening of the chromosome ends synthesizing DNA back onto chromosome ends by reverse transcriptase (Greider and Blackburn, 1987). Two distinct molecules compose the enzyme, one made of RNA and another one made of protein. The RNA is used as a template for the addition of multiple telomeric repeat sequences. The combination of both portions makes active telomerase that can lengthen telomeres. Telomere proteins probably affect the accessibility of telomeric DNA to telomerase and interact with other structural or regulatory proteins (Fang and Cech, 1995).

Chong et al. (1995) identified and cloned a major protein component of human telomeres (TRF factor) showing by means of immunofluorescent labeling that TRF specifically colocalizes with telomeric DNA at chromosome ends. This observation allowed them to prove that the telomeric TTAGGG repeat array forms a specialized nucleoprotein complex.

Luderus et al. (1996), using FISH analysis, showed that TRF is an integral component of the telomeric complex and that the presence of TRF on telomeric DNA correlates with the compact configuration of telomeres.

The double-stranded TTAGGG long tandem array of human telomeres are packaged by a telomere repeat binding factor, hTRF1, that comprises three helices similar to that of each Rap1p of a yeast telomeric protein Rap 1p. Nishikawa et al. (1998) showed that TRF1 DNA domain is likely to bind to DNA in a similar manner to that of the second subdomain of Rap1p. Apparently, in human cells the telomere length is controlled by the telomeric protein TRF1 (van Steensel and de Lange, 1997). Besides, Zalensky et al. (1997) identified a novel protein in sperm cells that binds to the double-stranded telomeric repeat (TTAGGG) forming several nucleoprotein complexes.

Moyzis et al. (1988), using fluorescence in situ hybridization, also observed that most of the terminal fluorescent signals are not localized at the chromatid ends, but are surrounded by chromatin material. Day et al. (1993) claimed that repetitious DNA and proteins could intervene protecting the chromosome end from degradation and break rejoining. Smith and de Lange (1997) found that telomeric DNA preserves binding sites for telomeric proteins which form a protective nucleoprotein complex at chromosome ends.

Hsu et al. (1999) suggested the existence of a direct link between highly expressed Ku heterodimer protein and mammalian telomeres since it is a high-affinity DNA binding component and critical for non-homologous DNA double-stranded break repair. Using an in vivo crosslinking method they found that human and hamster telomeric DNAs specifically coimmunoprecipitate with human Ku 80 after crosslinking. Tommerup et al. (1994) hypothesized that mammalian telomeres have a bipartite structure with unusual chromatin near the telomere terminus and a more common nucleosomal organization in the proximal part of the telomere. Slijepcevic et al. (1997) speculated that the capacity of chromosomes to fuse in mammalian cells may be determined not only by telomere length but also by the status of telomeric chromatin structure, observing that telomere associations are more frequent in cell lines exhibiting longer telomeres. Boulton and Jackson (1998) supported the interesting view that the abundant protein bound to double-stranded DNA Rap 1p apparently intervenes in regulating telomere length.

\section{THE TELOMERIC/SUBTELOMERIC PICTURE: (III)}

The microscopist view: perceiving the problems?

\section{Scanning microphotometry in chromosome research}

Scanning microscope photometry has been extensively used for image analysis of nuclei and chromosomes as well as for automated karyotyping. Color graphic terminals, software development and appropriate data manipulation have expanded the scope of quantitative scanning microphotometry that became particularly useful for quantitative analysis in several cytogenetical problems. We carried out an extensive research in our Laboratory along the decades trying to apply this computer graphic technology to specific cytogenetical problems developing instrumentation and dedicated software (Drets and Monteverde, 1987). The interactive system thus developed allowed the microphotometrical scanning of human G-, R-, C- and T-banded chromosomes and the quantitative localization of the highest band densitometric peaks and band-interband junctions (Drets et al., 1989). Besides, this procedure of computerized morphometric measurements enabled to draw graphic quantitative maps and to redefine chromosome banding patterns and karyotype description, all of which has proved to be useful in molecular cytogenetics (Drets et al., 1994). The new quan- 
titative and visual information given by the interactive graphic method contributed thus to a more informative understanding of the nuclear and chromosome structure (Drets et al., 1995a).

\section{Differential distribution of the highest densities detected in subtelomeric areas}

Microphotometrical scanning of chromosome regions stained with the T-banding method developed by Dutrillaux (1973) showed that the high density chromatin of the T-banded subtelomeric chromosomes of normal human and $\mathrm{CHO}$ chromosomes is distributed in a specific manner at the subtelomeric segment namely: a) of similar size in both sister chromatids; b) predominating in one of the chromatids, and c) concentrated in only one chromatid (Figure 1, column A). Pixel count corresponding to the highest sorted absorbance values allowed the following quantitative classification: a) when the inter- chromatid difference of highest absorbance values was less than $25 \%$ the distribution was considered as identical and identified as type 1; b) differences of 25 to $75 \%$ were classified as type 2, and c) differences higher than $75 \%$ as type 3 (Drets et al., 1992a).

\section{THE MODEL: ENDOREDUPLICATED CHROMOSOMES AS A TEST OF THE EXISTENCE OF CHROMOSOME DENSITY PATTERNS}

Endoreduplicated chromosomes offer a unique opportunity to confirm if the density patterns detected by scanning microphotometry were real structures and if they were able to replicate reproducing in sister chromosomes the same subtelomeric structure in terms of high density stain distributions as is found in normal human and $\mathrm{CHO}$ chromosomes.

The images produced by T-banded endoreduplicated chromosomes confirmed not only that the density patterns
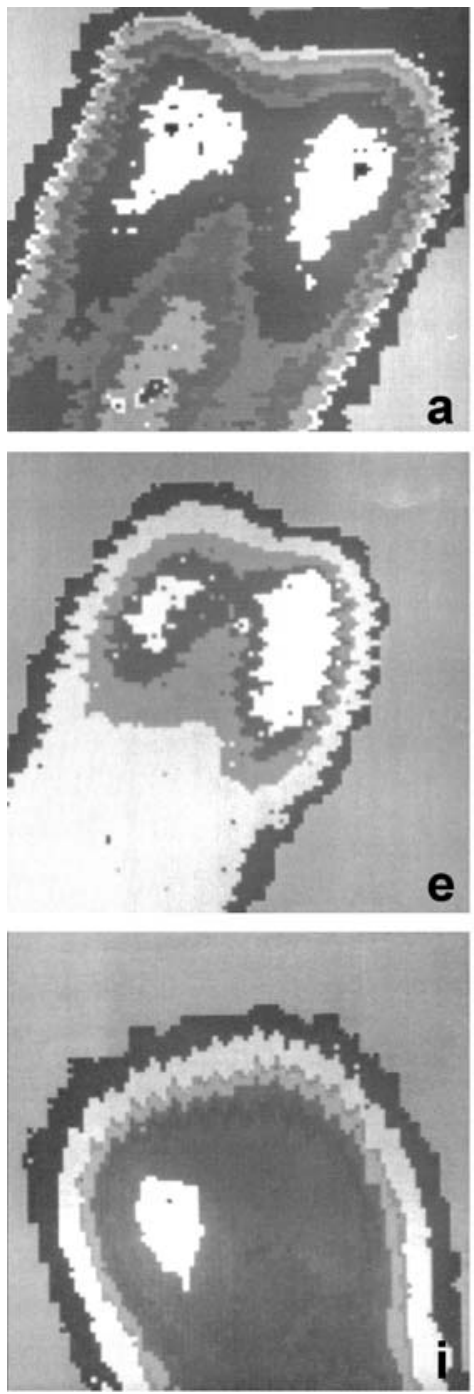

A
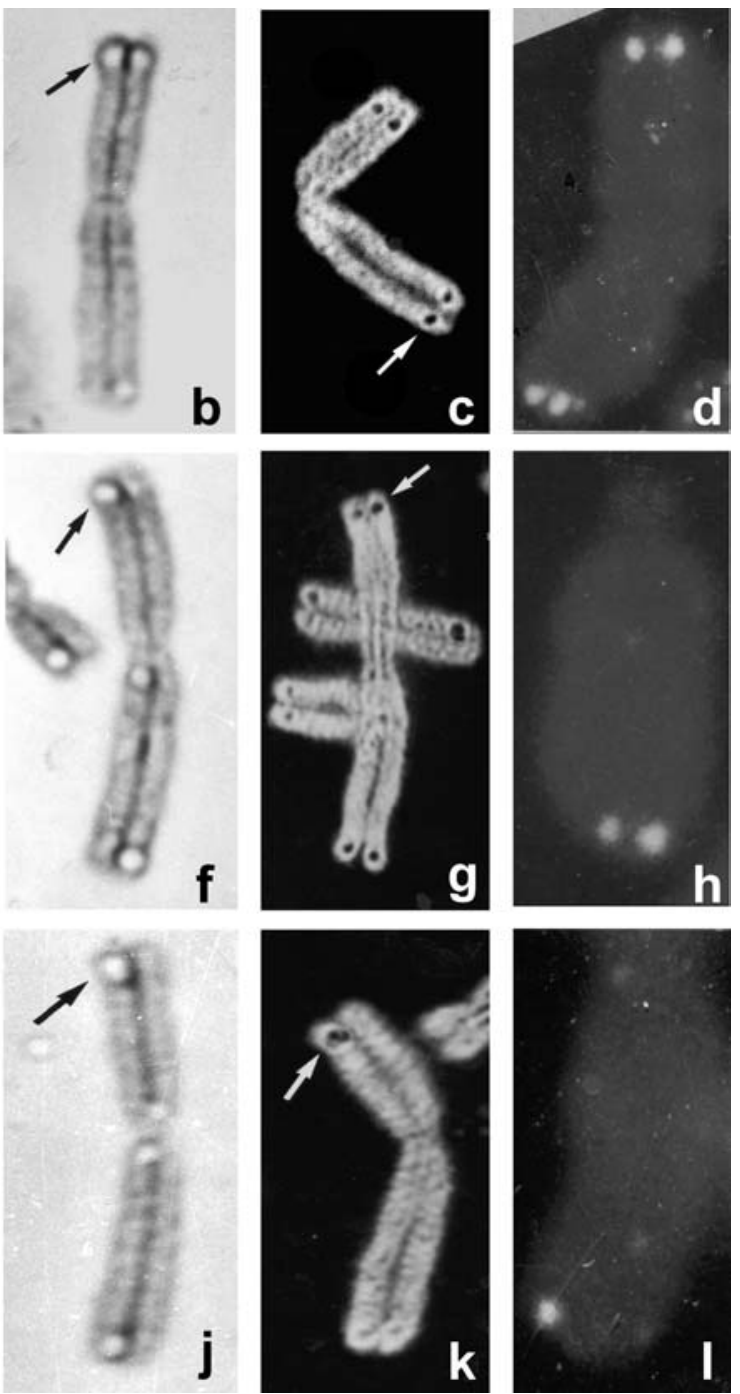

B

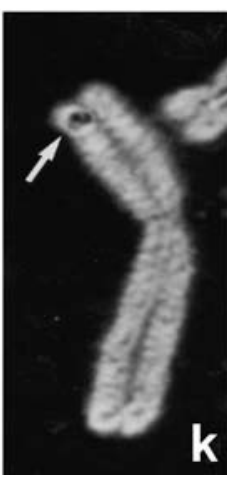

C

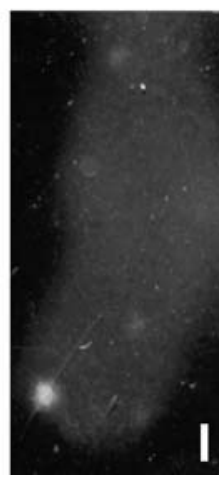

D
Figure 1 - Comparison of size and localization of high densities, induced holes and telomeric probes in normal $\mathrm{CHO}$ and human chromosomes as observed with different methods. Column A, Graphic images of subtelomeric high densities obtained by microphotometric scanning of T-banded $\mathrm{CHO}$ chromosomes; columns $\mathbf{B}$ and $\mathbf{C}$, holes as observed with phase and reflection microscopy, respectively; column $\mathbf{D}$, human chromosomes labeled with a telomeric fluorescent probe. Upper row: High densities (density pattern type 1 ; a) as well as holes and fluorescent signals are of similar size in both chromatids. Middle row: Higher density (type 2; e) and a larger hole (f, g) and fluorescent signal $(\mathrm{h})$ are seen predominating in one chromatid. Lower row: (i) Subtelomeric high density is concentrated in one chromatid (type 3; i); holes in only one chromatid ( $\mathrm{j}$ and $\mathrm{k}$ ), and one fluorescent signal (1) are observed 
detected were comparable to the three types of density distribution observed in normal T-banded $\mathrm{CHO}$ chromosomes, but also that their structures were able to replicate, appearing to be of similar size in sister chromosomes (Figure $2 \mathrm{a}-\mathrm{c})$. Therefore, the natural conclusion from these observations was that the high density patterns detected by scanning microphotometry were not an artifact or the result of computer manipulations but details of the terminal structure of the metaphase chromosome (Drets and Mendizábal, 1998a and b).

\section{Specific removal of portions of subtelomeric segments}

We found that prolonging the incubation time of human and $\mathrm{CHO}$ chromosomes in the hot T-banding buffer produces tiny holes in subtelomeric regions of sister chromatids. The treatment also induces holes in paracentric segments of some chromosomes (Figure 1, columns B and C). These holes appeared in one sister chromatid or in both. In some chromosomes these holes were of similar size while in other cases they were different in size, their localization being comparable to the areas of high density (Drets et al., 1992b).

\section{THE MODEL: PRODUCTION OF HOLES IN ABERRANT CHO CHROMOSOMES}

The finding of holes in normal chromosomes raised the question if they were artifacts produced randomly by prolonged incubation in the hot buffer. To answer this question, aberrant T-banded chromosomes obtained by treating CHO cells with AluI (5 units) in $1.1 \mathrm{M}$ glycerol were used. The procedure is able to induce a variety of chromosome aberrations, mainly dicentrics, triradials and quadriradials in a considerable number of metaphases (Obe and Winkel, 1985). We considered that these types of aberrant chromosomes were ideal materials to determine the specificity of the production of holes. We found that holes were induced in subtelomeric and in paracentric segments as expected in any type of aberrant chromosome. Since it is practically impossible to induce holes in specific subtelomeric areas of complex aberrant chromosomes (i.e., triradials or quadriradials; see Figure $3 a$ and $b$ ), we con- cluded that the method produced a specific removal of chromatin through still unknown mechanisms (Drets et al., 1995b).

The subtelomeric structure: questions, obscurities and beyond

Microphotometrical scanning of subtelomeric Tbanded chromosome segments and computer graphic analyses have shown that the T-banded terminal segments of $\mathrm{CHO}$ and human chromosomes present a complex chromatin density distribution (Drets et al., 1992a). Complex terminal heterochromatic chromosome substructures were described by Lima-De-Faria (1952) and Lima-De-Faria and Sarvella (1958) at the light microscope level in plant pachytene chromosomes. The different types of graphic images produced by the system closely corresponded to the T-banded segments observed with the light microscope. However, the computer graphic method used gave a more visual and quantitative insight into T-banded areas of chromosomes than the usual light microscopic analyses. The distribution of the three types of high density patterns found in sister chromatids of endoreduplicated CHO chromosomes strongly suggested that they are real cytological facts, probably reflecting the underlying chromatin organization.

Chromosomes stained with Hoechst and DAPI showed that DNA is lost from the subtelomeric and paracentric areas during the induction of chromosome holes. We could not detect even a single case of a pale fluorescence inside holes suggesting that they were empty, though the rest of the chromosomes were still able to fluoresce, showing remnants of R-fluorescent banding patterns. Apparently, prolonged exposure to the hot T-buffer initiates the denaturing of specific segments in the subtelomeric and paracentric areas presenting similar reactivities, with subsequent chromatin disorganization resulting in holes that can be seen with the light microscope (Drets et al., 1995b). Since the hole induction occurs where the highest density chromatin areas are detected by scanning microphotometry these phenomena may be related.

The specific and complex density patterns found in the subtelomeric segments and the induction of holes in normal and aberrant chromosomes topologically matched
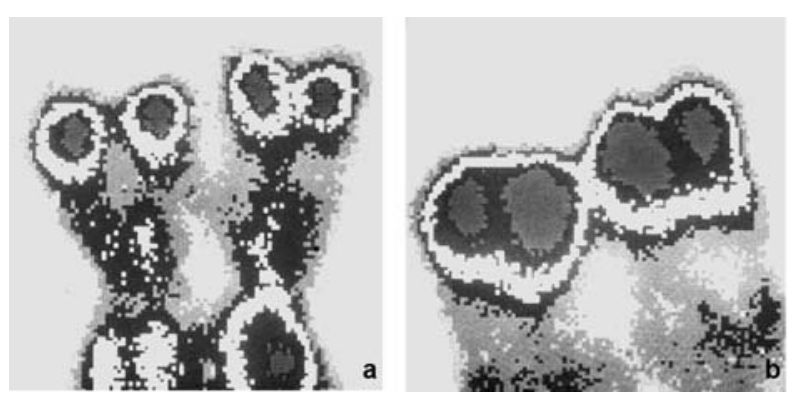

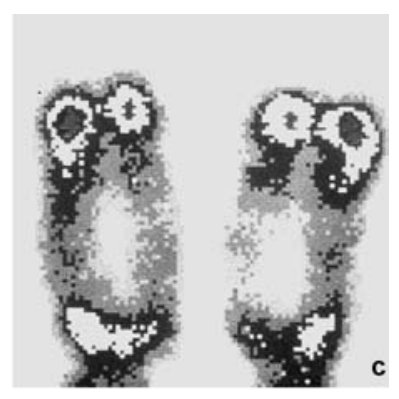

Figure 2 - a-c, Replication high density patterns in endoreduplicated $\mathrm{CHO}$ chromosomes. The graphic images closely corresponded to the density paterns detected in normal chromosomes. 


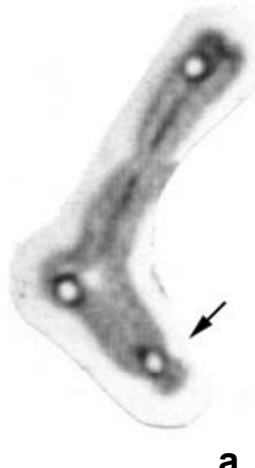

a

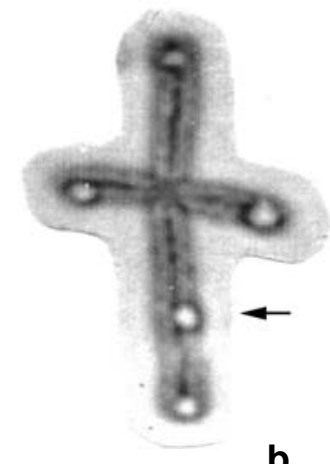

Figure 3 - a and b, Trirradial and quadriradial aberrant $\mathrm{CHO}$ chromosomes showing holes induced in subtelomeric and paracentric areas (arrows).

the observations made on the localization and distribution of telomeric fluorescent signals (Figure 1, column D). Interestingly, biotinilated fluorescent telomeric probes usually show signals of variable size, number and position in sister chromatids, resembling the distribution of the high density patterns detected by microphotometric scanning of T-banded chromosomes (Schubert, 1992). On the other hand, the immunofluorescent protein-labeled metaphase published by Chong et al. (1995) shows fluorescent signals appearing of similar or different size in both chromatids or, in some chromosomes, in only one chromatid, resembling the different subtelomeric density patterns that we found.

Furthermore, it is also not well understood how the underlying chromosomal organization influences the banding phenomena. Chromosome banding patterns are revealed by most of the reported procedures (G-, C-, R-, and T-banding) because Giemsa stains specific chromosome structures. Comings and Avelino (1974) extensively investigated the binding of Giemsa dyes to chromatin during the banding treatment, showing that thiazins specifically interact with the phosphate groups of DNA and side stack along the molecule. The microphotometrical detection of different density patterns suggests that they are related not only to the banding procedure but also to the specific staining of T-banded segments by Giemsa stain. In this connection, Sumner (1990) pointed out that in banding, dye accessibility may be modified either by proteins or by the variation in DNA base pair composition along the genome (or both).

Usually, the incubation of chromosomes in the Tbuffer produces dark R-bands. Although R-bands fade with increasing heat-treatment time, T-bands are a subset of R-bands extremely resistant to heat and to digestion with the restriction endonuclease MseI (Ludeña et al., 1991). Allen et al. (1988) also described the T-bands of human chromosomes as intricate fibrous structures seen with electron microscopy, showing that subtelomeric areas of metaphase chromosomes are extremely complex struc- tures. Holmquist (1992) claimed that four classes of Rbands exist, differing in their combination of extreme $A l u$ richness and extreme GC richness.

Even though molecular analysis of the telomeric/ subtelomeric DNA and associated protein complexes has accumulated considerable information on its structure, a clear picture of the eukaryotic metaphase chromosome at a high organization level is still missing. An interesting approach has been reported by Saitoh and Laemmli (1994), indicating that the bands of the metaphase chromosome structure arise from a differential folding path of the highly AT-rich scaffold using the highly AT-specific fluorochrome daunomycin. Although the proposed loop-scaffold model fits well with most of the metaphase chromosome structure, the high content of R-banding material found in the Tbanded segments makes it difficult to make a convincing and comprehensive interpretation of the many facts observed in this region using this model.

In an enlightening recent review Pardue and DeBaryshe (1999) stressed the point that several findings suggest that eukaryotic telomeres may play functions other than chromosome end protection and recognition of intact chromosomes.

Jeppessen (1997) showed that human metaphase chromosomes contain hyperacetylated histone $\mathrm{H} 4$, which marks the position of potentially active gene sequences on metaphase chromosomes. Histone $\mathrm{H} 4$ is non-uniformly distributed and clustered in chromatin domains that generally correspond with the R-bands with strongest immunolabelling in T-bands. Recently, Folle et al. (1998) detected that endonucleases $A l u \mathrm{I}, B a m \mathrm{HI}$, DNaseI, neutrons and gamma rays produce breakpoint clusters non-randomly distributed in $\mathrm{CHO}$ chromosomes, appearing in highly acetylated chromosome segments. These authors claim that breakpoint clusters induced by endonucleases and ionizing radiations would be induced predominantly in less tightly packed chromatin where histone $\mathrm{H} 4$ is hyperacetylated, facilitating DNA accessibility to endonucleases (MartínezLópez et al., 2000). Clear peaks of these breakpoint clusters were found to be particularly intense in the subtelomeric segments where the density patterns and chromosome holes induced were found, suggesting that these chromosome segments are singular genomic areas presenting a complex structural composition and probably play some functional role.

The density pattern distribution observed in nonendoreduplicated and endoreduplicated chromosomes may indicate that it is dependent on the localized distribution of DNA-protein complexes, possibly reflecting different functional stages of the region, though these still need to be demonstrated. An additional clue that the subtelomeric regions could possess some specific functional activity is the observation of minute sister chromatid exchanges detected by scanning microphotometry in T-banded CHO chromosomes (Drets et al., 1992a).

Summarizing, in this brief review we present eviden- 
ce of the existence of over-looked structures and reactivities of the subtelomeric chromosome region and we discuss their possible structural and functional significance. As Therman (1995) sagaciously pointed out about other still obscure cytogenetical problems, it may be extremely informative to make combined molecular and microscope observations on large subtelomeric chromosome segments. This may lead to a better understanding of their structural role within the nucleus; however, this awaits biochemical and genetic definition. The most fascinating work on the structure of the metaphase chromosome may still be ahead.

\section{ACKNOWLEDGMENTS}

The author thanks G.A. Folle and W. Martínez-López for their valuable critical review of the manuscript. The human telomeric labeled chromosomes were obtained by courtesy of Dr. R. Bonomi. Help with editorial image processing done by M. Lalinde is also grateful acknowledged. Research supported in part by the Program for Development of Basic Sciences (PEDECIBA), Uruguay.

\section{REFERENCES}

Allen, T.D., Jack, E.M. and Harrison, C.J. (1988). The three dimensional structure of human metaphase chromosomes determined by scanning electron microscopy. In: Chromosomes and Chromatin (Adolph, K.W., ed.). Vol. II. CRC Press Inc., Florida, pp. 51-72.

Balajee, A.S., Oh, H.J. and Natarajan, A.T. (1994). Analysis of restriction enzyme-induced chromosome aberrations in the interstitial telomeric repeat sequences of $\mathrm{CHO}$ and CHE cells by FISH. Mutat. Res. 307: 307-313.

Bedbrook, J.R., Jones, J., O'Dell, M., Thompson, R.D. and Flavell, R.B. (1980). A molecular description of telomeric heterochromatin in Secale species. Cell 19: 545-560.

Blackburn, E.H. and Gall, J.G. (1978). A tandemly repeated sequence at the termini of the extrachromosomal ribosomal RNA genes in Tetrahymena. J. Mol. Biol. 120: 33-53.

Blackburn, E.H. and Greider, C.W. (1995). Telomeres. Cold Spring Harbor Laboratory Press, Cold Spring Harbor, NY.

Blackburn, E.H. and Szostak, J.W. (1984). The molecular structure of centromeres and telomeres. Annu. Rev. Biochem. 53: 163-194.

Boulton, S.J. and Jackson, S.P. (1998). Components of the Ku-dependent non-homologous end-joining pathway are involved in telomeric length maintenance and telomere silencing. EMBOJ. 17: 1819-1828.

Chong, L., van Steensel, B., Broccoli, D., Erdjument-Bromage, H., Hanish, J., Tempst, P. and de Lange, T. (1995). A human telomeric protein. Science 270: 1663-1667.

Comings, D.E. and Avelino, E. (1974). Mechanisms of chromosome banding. VII. Interaction of methylene blue with DNA and chromatin. Chromosoma 51:365-379.

Day, J.P., Marder, B.A. and Morgan, W.F. (1993). Telomeres and their possible role in chromosome stabilization. Environ. Mol. Mutagen. 22:245-249.

Drets, M.E. and Mendizábal, M. (1998a). Microphotometrical image analysis of the subtelomeric region of the T-banded endoreduplicated chromosomes of Chinese hamster ovary (CHO) cells. Genet. Mol. Biol. 21: 219-225.

Drets, M.E. and Mendizábal, M. (1998b). The underlying structure of the subtelomeric segments detected by microphotometrical scanning and graphic image analysis. Fundamental and Molecular Mechanisms of Mutagenesis. Mutat. Res. 404: 13-16.

Drets, M.E. and Monteverde, F.J. (1987). Automated cytogenetics with modern computerized scanning microscope photometer systems. In:
Cytogenetics. Basic and Applied Aspects (Obe, G. and Basler, A., eds.) Springer-Verlag, Berlin, Heidelberg, New York, pp. 48-64.

Drets, M.E., Folle, G.A. and Monteverde, F.J. (1989). Quantitative detection of chromosome structures by computerized microphotometric scanning. In: Chromosomal Aberrations. Basic and Applied Aspects (Obe, G. and Natarajan, A.T., eds.). Springer-Verlag, Berlin, Heidelberg, New York, pp. 1-12.

Drets, M.E., Obe, G., Monteverde, F.J., Folle, G.A., Medina, I.I., De Galvez, M.G., Duarte, J.E. and Mechoso, BH. (1992a). Computerized graphic and light microscope analyses of T-banded chromosome segments of Chinese hamster ovary cells and human lymphocytes. Biol. Zentralbl. 111: 204-214.

Drets, M.E., Obe, G., Folle, G.A., Medina, I.I., De Galvez, M.G., Duarte, J.E. and Mechoso, B.H. (1992b). Appearance of "holes" in subtelomeric regions of human and Chinese hamster ovary cell chromosomes due to prolonged incubation in T-banding buffer followed by Giemsa staining. Rev. Bras. Genet. 15: 927-933.

Drets, M.E., Folle, G.A., Martínez, W., Bonomi, R., Duarte, J.E., Mechoso, B.H. and Larrañaga, J. (1994). Quantitative localization of chromatid breaks induced by AluI in the long arms of chromosome number 1 of Chinese hamster ovary $(\mathrm{CHO})$ cells by microphotometric scanning. In: International Symposium: Chromosomal Aberrations. Origin and Significance (Obe, G. and Natarajan, A.T., eds.). Springer-Verlag, Berlin, Heildelberg, New York, pp. 169-183.

Drets, M.E., Drets, G.A., Queirolo, P.J. and Monteverde, F.J. (1995a). Computer graphics as a tool in cytogenetic research and education. Comput. Appl. Biosci. 11: 463-468.

Drets, M.E., Mendizábal, M., Boccardo, E.M. and Bonomi, R. (1995b). Further analyses of subtelomeric and paracentric holes induced in human and Chinese hamster ovary cell chromosomes. Biol. Zentralbl. 114:329-338.

Dutrillaux, B. (1973). Nouveau système de marquage chromosomique: Les bandes T. Chromosoma 41:395-402.

Fang, G. and Cech, T.R. (1995). Telomere proteins. In: Telomeres (Blackburn, E.H. and Greider, C.W., eds.). Cold Spring Harbor Laboratory Press, Cold Spring Harbor, pp. 69-105.

Folle, G.A., Martínez-López, W., Boccardo, E. and Obe, G. (1998). Localization of chromosome breakpoints: implication of the chromatin structure and nuclear architecture. Mutat. Res. 404: 17-26.

Greider, C.W. (1998). Telomerase activity, cell proliferation, and cancer. Proc. Natl. Acad. Sci. USA 95: 90-92.

Greider, C.W. and Blackburn, E.H. (1987). The telomere terminal transferase of Tetrahymena is a ribonucleoprotein enzyme with two kinds of primer specificity. Cell 51: 887-898.

Henderson, E. (1995). Telomere DNA structure. In: Telomeres (Blackburn, E.H. and Greider, C.W., eds.). Cold Spring Harbor Laboratory Press, Cold Spring Harbor, pp. 11-34.

Holmquist, G.P. (1992). Review article: Chromosome bands, their chromatin flavors and their functional features. Am. J. Hum. Genet. 51: 17-37.

Hsu, H.L., Gilley, D., Blackburn, E.H. and Chen, D.J. (1999). Ku is associated with the telomere in mammals. Proc. Natl. Acad. Sci. USA 96: 12454-12458.

Jeppesen, P. (1997). Histone acetylation: a possible mechanism for the inheritance of cell memory at mitosis. BioEssays 19: 67-74.

Lima-De-Faria, A. (1952). Chromomere analysis of chromosome complement of rye. Chromosoma 5: 1-68.

Lima-De-Faria, A. and Sarvella, P. (1958). The organization of telomeres in species of Solanum, Salvia, Scilla, Secale, Agapanthus and Ornithogalum. Hereditas 44: 337-346.

Ludeña, P., Sentis, C., De Cabo, F., Velazquez, M. and Fernandez-Piqueras, J. (1991). Visualization of R-bands in human metaphase chromosomes by the restriction endonuclease MseI. Cytogenet. Cell Genet. 57: 8286.

Luderus, M.E., van Steensel, B., Chong, L., Sibon, O.C., Cremers, F.F. and de Lange, T. (1996). Structure, subnuclear distribution, and nuclear matrix association of the mammalian telomeric complex. J. Cell Biol. 135: 867-881.

Martínez-López, W., Folle, G.A., Obe, G. and Jeppesen, P. (2000). Chromosome regions enriched in hyperacetylated histone $\mathrm{h} 4$ are preferred sites for endonuclease- and radiation-induced breakpoints. Chromosome Res. (in press). 
Meyne, J., Baker, R.J., Hobart, H.H., Hsu, T.C., Ryder, O.A., Ward, O.G., Wiley, J.E., Wurster-Hill, D.H., Yates, T.L. and Moyzis, R.K. (1990a). Distribution of non-telomeric sites of the (TTAGGG) $)_{n}$ telomeric sequence in vertebrate chromosomes. Chromosoma 99: 3-10.

Meyne, J., Ratliff, R.L., Buckingham, J.M., Jones, M.D., Wilson, J.S. and Moyzis, R.K. (1990b). The human telomere. In: Chromosomes Today (Fredga, K., Kihlman, B.A. and Bennet, M.D., eds.). Unwin Hyman, London, pp. 75-80.

Moyzis, R.K., Buckinham, J.M., Cram, L.S., Dani, M., Deaven, L.L., Jones, M.D., Meyne, J., Ratliff, R.L. and Wu, J.R. (1988). A highly conserved repetitive DNA sequence (TTAGGG)n present at the telomeres of human chromosomes. Proc. Natl. Acad. Sci. USA 85: 6622-6626.

Nishikawa, T., Nagadoi, A., Yoshimura, S., Aimoto, S. and Nishimura, Y. (1998). Solution structure of the DNA-binding domain of human telomeric protein, hTRF1. Structure 6: 1057-1065.

Obe, G. and Winkel, E.-U. (1985). The chromosome-breaking activity of the restriction endonuclease $A l u \mathrm{I}$ in CHO cells is independent of the S phase of the cell cycle. Mut. Res. 152: 25-29.

Pardue, M.L. and DeBaryshe, P.G. (1999). Telomeres and telomerase: more than the end of the line. Chromosoma 108: 73-82.

Poon, S.S.S., Martens, U.M., Ward, R.K. and Landsdorp, P.M. (1999). Telomere length measurements using digital fluorescence microscopy. Cytometry 36: 267-278.

Saiga, H. and Edstrom, J.E. (1985). Long tandem arrays of complex repeat units in Chironomus telomeres. EMBO J. 4: 799-804.

Saitoh, Y. and Laemmli, U.K. (1994). Metaphase chromosome structure: bands arise from a differential folding path of the highly AT-rich scaffold. Cell 76: 609-622.

Schubert, I. (1992). Telomeric polymorphism in Vicia faba. Biol. Zentralbl. 111: 164-168.
Slijepcevic, P., Hande, M.P., Bouffler, S.D., Landsdorp, P. and Bryant, P.E. (1997). Telomere length, chromatin structure and chromosome fusigenic potential. Chromosoma 106: 413-421.

Smith, S. and de Lange, T. (1997). TRF1, a mammalian telomeric protein. Trends Genet. 13: 21-26.

Steinmüller, J., Schleiermacher, E. and Scherthan, H. (1993). Direct detection of repetitive whole chromosome paint and telomere DNA probes by immunogold electron microscopy. Chromosome Res. 1: 45-51.

Sumner, A.T. (1990). Chromosome Banding. Unwin Hyman, London.

Therman, E. (1995). Chromosome Behaviour and Cell Differentitation: A Field Ripe for Exploration? Perspectives. Anecdotal, Historical and Critical Comments on Genetics (Crow, J.F. and Dove, W.F., eds.). Genetics 141: 799-804.

Tommerup, H., Dousmanis, A. and de Lange, T. (1994). Unusual chromatin in human telomeres. Mol. Cell. Biol. 14: 5777-5785.

van Steensel, B. and de Lange, T. (1997). Control of telomere length by the human telomeric protein TRF1. Nature 385: 740-743.

Wells, R.A., Germino, G.G., Krishna, S., Buckle, V.I. and Reeders, S.T. (1990). Telomere-related sequences at interstitial sites in the human genome. Genomics 8: 699-704.

Young, B.S., Pession, A., Traverse, K.L., French, C. and Pardue, M.L. (1983). Telomere regions in Drosophila share complex DNA sequences with pericentric heterochromatin. Cell 34: 85-94.

Zakian, V.A. (1989). Structure and function of telomeres. Ann. Rev. Genet. 23: 579-604

Zalensky, A.O., Tomilin, N.V., Zalenskaya, I.A., Teplitz, R.L. and Bradbury, E.M. (1997). Telomere-telomere interactions and candidate telomere binding protein(s) in mammalian sperm cells. Exp. Cell Res. 232: 29-41.

(Received November 23, 2000) 
